\title{
PEMBUATAN DAN KARAKTERISASI KATALIS ZnO/KARBON AKTIF DENGAN METODE SOLID STATE DAN UJI AKTIFITAS KATALITIKNYA PADA DEGRADASI RHODAMIN B
}

\author{
Upita Septiani*, Ilona Bella, dan Syukri \\ Laboratorium Kimia Material, Jurusan Kimia FMIPA, Universitas Andalas \\ Kampus Limau Manis Padang-25163, Indonesia \\ e-mail: upitas@yahoo.com
}

\begin{abstract}
Composite catalyst $\mathrm{ZnO} /$ Activated Carbon $(\mathrm{ZnO} / \mathrm{AC})$ had been synthesized successfully by solid state method. Synthesis was done by varying the addition of activated carbon (AC) $2 \%$, $5 \%$, and $10 \% \mathrm{ZnO}$ mass. Composite catalyst were calcinated at $400^{\circ} \mathrm{C}$ and characterized by FTIR (Fourier Transform Infra Red), XRD (X-Ray Diffraction), SEM (Scanning Electron Microscopy). Based on the results of FTIR, absorption appeared in the region wave number $1400-1600 \mathrm{~cm}^{-1}$, which indicated stretching of $\mathrm{C}=\mathrm{C}$ was assumed come from AC. From the XRD results, it was known by the addition of AC, not overly change the crystallinity and crystal size of $\mathrm{ZnO}$, the crystal structure is hexagonal (wurtzite). SEM images showed AC prevented the agglomeration of $\mathrm{ZnO}$ that would expand the surface area of $\mathrm{ZnO}$ and increased catalytic activity of $\mathrm{ZnO}$. For the results of the catalytic activity test, catalyst $\mathrm{ZnO} / \mathrm{AC}$ was tested on the degradation of Rhodamine B solution (10 ppm) by UV light irradiation, where the increasing number of trains the catalytic ability of $\mathrm{ZnO}$ also increased, it could be concluded that activated carbon can support to increase the role of $\mathrm{ZnO}$ in degrading Rhodamine $\mathrm{B}$.
\end{abstract}

Keywords: composite catalyst, $\mathrm{ZnO}$, activated carbon, solid state, Rhodamine B

\section{PENDAHULUAN}

Belakangan ini semikonduktor berbasis reaksi fotokatalitik telah banyak menarik perhatian. Diantara berbagai macam semikonduktor, $\mathrm{ZnO}$ merupakan salah satu semikonduktor anorganik yang tidak bersifat toksik yang dapat memberikan mobilitas tinggi dan stabilitas termal yang baik. $\mathrm{ZnO}$ memiliki jarak pita 3,37 eV dengan energi ikatan $60 \mathrm{meV}$ pada suhu ruang dengan struktur yang stabil yaitu wurtzite ${ }^{[1]}$. Banyak penelitian yang dilakukan dengan menggunakan $\mathrm{ZnO}$ sebagai katalis, baik $\mathrm{ZnO}$ sebagai monokatalis, $\mathrm{ZnO}$ yang didoping dengan sesama logam (metal-metal) maupun yang didoping dengan senyawa non logam (metal-non metal) karena sifatnya yang serbaguna, kemudahan dalam pembuatan, dan biaya yang relatif murah $h^{[2,3,4]}$.

Karbon aktif adalah suatu bahan hasil proses pirolisis arang pada suhu $600-900^{\circ} \mathrm{C}$. Bentuk dominannya adalah karbon amorf yang memiliki luas permukaan yang luar biasa besar dan volume pori. Karakteristik unik ini terkait dengan sifat daya serapnya, yang dimanfaatkan dalam berbagai aplikasi fase cair maupun fase gas. Karbon aktif adalah adsorben yang sangat serbaguna karena ukuran dan distribusi pori-pori di dalam matriks karbon dapat dikontrol untuk memenuhi kebutuhan pasar saat ini ${ }^{[5]}$. 
Adapun salah satu aplikasnya adalah sebagai adsorben yang sering digunakan pada industri tekstil untuk menghilangkan warna dan mempunyai efektifitas tinggi untuk menyerap berbagai tipe zat warna ${ }^{[6]}$.

Beberapa keuntungan yang diharapkan dari penyesuaian $\mathrm{ZnO}$ pada karbon aktif diantaranya karbon aktif merupakan kandidat yang cocok untuk adsorben sebagai pendukung dalam proses adsorbsi-katalitik karena dengan adanya karbon aktif dapat meningkatkan microporosity dan luas permukaan yang tinggi, sehingga memiliki daya adsorpsi yang baik. $^{[7]}$ Material $\mathrm{ZnO}$ yang dimodifikasi dengan penambahan karbon aktif menjadi sebuah material komposit yang memiliki fungsi ganda yaitu sebagai adsorben dari sifat karbon aktif yang berpori serta sebagai fotokatalis yang berasal dari ZnO. Dalam beberapa penelitian sebelumnya juga telah dilakukan pembuatan katalis $\mathrm{ZnO}$ yang disupport karbon aktif yaitu dengan beberapa metode seperti mikro emulsi, proses solvotermal dengan etanol ${ }^{[7,8]}$.

Pada penelitian ini, sintesis katalis $\mathrm{ZnO}$ /karbon aktif dilakukan dengan menggunakan metode solid state. Katalis yang terbentuk dikarakterisasi dengan FTIR (Fourier Transform Infra Red), XRD (X-Ray Diffraction), SEM (Scanning Electron Microscopy) yaitu untuk melihat bagaimana katalis yang terbentuk, serta uji aktifitas fotokatalitiknya dalam mendegradasi Rhodamin B.

\section{METODOLOGI PENELITIAN}

\section{Bahan Kimia, Peralatan dan Instrumentasi}

Bahan-bahan yang digunakan adalah seng oksida ( $\mathrm{ZnO})$ (Merck), karbon aktif (Merck), Rhodamin B, dan akuades.

Peralatan yang digunakan antara lain beberapa peralatan gelas, neraca analitis, hot plate \&magnetic stirer, oven, furnace, corong Buchner, cawan petri $(\mathrm{d}=13,5 \mathrm{~cm})$, lampu merkuri $(\lambda=365 \mathrm{~nm})$, sentrifus, nano milling. Instrumen yang digunakan adalah Fourier Transform Infra Red (FTIR; JASCO FT-IR 460 plus), XRay Diffraction (XRD;
Philip X'Pert Powder Type PW4030/60), Scanning Electron Microscopy (SEM; Phenom Pro X), serta Spektrofotometer UVVis.

\section{Prosedur Penelitian}

\section{Preparasi sampel $\mathrm{ZnO}$}

Sejumlah $\mathrm{ZnO}$ dihaluskan dengan menggunakan nanomiling selama \pm 1 jam, kemudian diaktifasi pada suhu $200^{\circ} \mathrm{C}$ selama 5 jam. Pada saat diaktifasi $\mathrm{ZnO}$ diaduk dengan menggunakan magnetic stirrer dan dibantu pengadukan secara manual dengan menggunakan batang pengaduk.

\section{Sintesis katalis ZnO/karbon aktif ( $\mathrm{ZnO} / \mathrm{KA})$}

Sebanyak $4 \mathrm{~g}$ ZnO yang telah diaktifasi, dicampurkan dengan $160 \mathrm{~mL}$ akuades untuk menghasilkan campuran $\mathrm{ZnO}$. Kemudian ditambahkan karbon aktif ke dalam campuran $\mathrm{ZnO}$ yang telah dibuat dengan perbandingan $2 \%$, 5\%, dan $10 \%$ karbon aktif terhadap massa $\mathrm{ZnO}$ yaitu $0,08 \mathrm{~g} ; 0,2 \mathrm{~g}$; dan $0,4 \mathrm{~g}$. Larutan $\mathrm{ZnO} / \mathrm{KA}$ yang telah divariasikan selanjutnya dimasukkan ke dalam labu alas bulat $500 \mathrm{~mL}$, labu dirangkai ke alat refluk dengan pendingin air dan dipanaskan pada temperatur $90^{\circ} \mathrm{C}$ selama 5 jam sambil diaduk menggunakan magnetic stirrer, kemudian disaring dengan penyaring Buchner. Penguapan pelarut disempurnakan dengan pengeringan menggunakan oven listrik pada temperatur $120^{\circ} \mathrm{C}$ hingga berat konstan. Katalis kering digerus dalam cawan porselin kemudian dikalsinasi pada temperatur $400^{\circ} \mathrm{C}$ selama 6 jam. Katalis yang telah terbentuk kemudian dikarakterisasi dengan FTIR, XRD, dan SEM ${ }^{[9]}$.

\section{Uji aktifitas fotokatalitik katalis

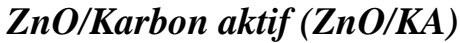

Aktifitas fotokatalitik katalis $\mathrm{ZnO} / \mathrm{KA}$ diuji terhadap degradasi Rhodamin B. Sebanyak 0,01 g Rhodamin B ditimbang, kemudian dilarutkan dengan akuades dalam labu 1000 $\mathrm{mL}$, didapatkan konsentrasi larutan Rhodamin B 10 ppm, selanjutnya diukur serapan serta absorban maksimumnya dengan spektrofotometer UV-Vis. Larutan tersebut diambil $20 \mathrm{~mL}$ dan ditambahkan 0,02 $\mathrm{g}$ katalis $\mathrm{ZnO} / \mathrm{KA}$ yang telah disintesis. Campuran tersebut kemudian disinari di bawah sinar UV dengan variasi lama waktu 
penyinaran 1, 2, dan 3 jam. Untuk koreksi pengurangan massa larutan akibat penguapan oleh panas yang timbul selama penyinaran dilakukan dengan menambahkan sejumlah akuades sesuai massa air yang hilang selama penyinaran. Setelah itu campuran disentrifus, serapan filtrat diukur dengan menggunakan Spektrofotometer UV-VIS. Cara yang sama juga dilakukan sebagai kontrol yaitu dengan menggunakan katalis $\mathrm{ZnO}$, serta tanpa menggunakan katalis ${ }^{[10]}$.

\section{HASIL DAN PEMBAHASAN}

\section{Karakterisasi Dengan FTIR}

Gambar 1.a merupakan spektrum FTIR ZnO murni. Spektrum ini memperlihatkan adanya pita serapan pada bilangan gelombang 420 $\mathrm{cm}^{-1}$ yang menandakan adanya vibrasi ulur dari Zn-O. Munculnya pita serapan pada bilangan gelombang 1250-1750 $\mathrm{cm}^{-}$ ${ }^{1}$ menunjukkan adanya vibrasi Zn-O-Zn. Selanjutnya pada daerah $3436 \mathrm{~cm}^{-1}$ dan 1637 $\mathrm{cm}^{-1}$ merupakan vibrasi $\mathrm{O}-\mathrm{H}$ stretching dan vibrasi $\mathrm{O}-\mathrm{H}$ bending dari molekul air yang terserap pada permukaan $\mathrm{ZnO}$.

Gambar 1.b merupakan spektrum FTIR karbon aktif, Dari spektrum memperlihatkan adanya pita serapan pada bilangan gelombang $3443 \mathrm{~cm}^{-1}$ yang menunjukkan adanya gugus hidroksil (-OH) pada karbon aktif, munculnya pita serapan pada daerah ini juga menunjukkan adanya adsorbansi gugus - CH yang tumpang tindih dengan adsorbansi $-\mathrm{OH}$ pada daerah tersebut. Kemudian terdapat serapan pada daerah antara 1400$1600 \mathrm{~cm}^{-1}$ yang menunjukkan adanya stretching $\mathrm{C}=\mathrm{C}$ dari karbon aktif, serapan pada $1384 \mathrm{~cm}^{-1}$ dan $1138 \mathrm{~cm}^{-1}$ menunjukkan adanya stretching C-O dan stretching C-O-C, dan tidak adanya pita-pita serapan pada daerah sidik jari kisaran bilangan gelombang $700-800 \mathrm{~cm}^{-1}$ menunjukkan bahwa karbon aktif bukan merupakan senyawa yang mengandung rantai alkil yang panjang ${ }^{[6,11]}$.

Gambar 1.c, d, dan e merupakan spektrum FTIR dari katalis $\mathrm{ZnO} / \mathrm{KA}$ dengan variasi KA 2\%, 5\%, dan 10\% (\%wt).

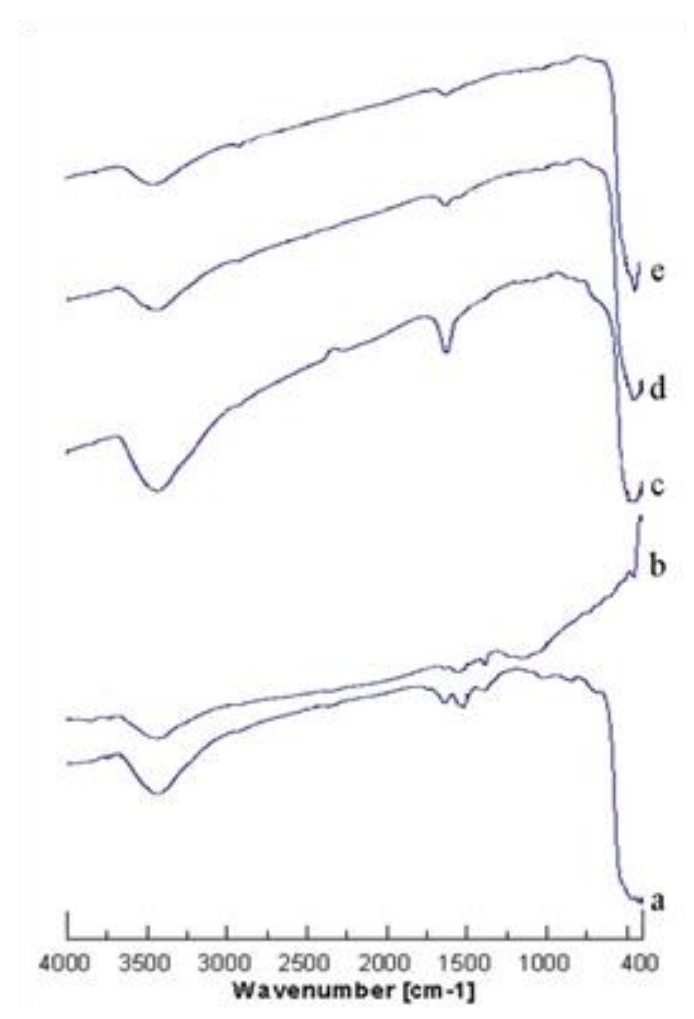

Gambar 1. Spektrum FTIR dari a.ZnO b.Karbon Aktif c.ZnO/KA 2\%d.ZnO/KA 5\% e. $\mathrm{ZnO} / \mathrm{KA} 10 \%$.

Memperlihatkan pola yang sama atau senada, dimana dengan penambahan karbon aktif $2 \%$, $5 \%$, dan $10 \%$ ternyata tidak terlalu memberikan perubahan yang signifikan pada spektrum $\mathrm{ZnO}$, yaitu serapan pada daerah 400-450 $\mathrm{cm}^{-1}$ menunjukkan adanya vibrasi ulur dari $\mathrm{Zn}-\mathrm{O}$, daerah 3400-an $\mathrm{cm}^{-1}$ merupakan stretching $\mathrm{O}-\mathrm{H}$ dari molekul air yang terserap pada permukaan $\mathrm{ZnO}$. Kemudian adanya serapan pada daerah 1600 $1680 \mathrm{~cm}^{-1}$ menunjukkan adanya stretching $\mathrm{C}=\mathrm{C}$ yang diasumsikan berasal dari karbon aktif, namun puncak serapan ini masih cukup lemah. Hal ini dimungkinkan karena jumlah karbon aktif yang digunakan cukup sedikit ${ }^{[6,}$ 11].

\section{Karaterisasi Dengan XRD}

Gambar 2.a merupakan pola difraksi sinar-X $\mathrm{ZnO}$ yang menunjukkan bahwa $\mathrm{ZnO}$ adalah kristal dengan memberikan intensitas yang dominan yaitu pada nilai $2 \theta 31,75 ; 34,40$; dan 36,22. Dengan membandingkan data dari ICDS No. 01-073-8765, puncak-puncak ZnO yang diukur menunjukkan kemiripan dengan puncak-puncak $\mathrm{ZnO}$ pada ICDS tersebut, ini 
mengindikasikan bahwa $\mathrm{ZnO}$ merupakan kristal yang memiliki struktur wurtzite (heksagonal), dengan ukuran kristal yang didapat dari perhitungan yaitu $54,481 \mathrm{~nm}$.

Gambar 2.b merupakan pola difraksi sinar-X karbon aktif. Dari gambar dapat dilihat bahwa karbon aktif bukan merupakan kristal tetapi amorf karena pola XRD karbon aktif tersebut tidak menunjukkan adanya puncakpuncak yang spesifik.

Gambar 2.c, d, dan e merupakan pola difraksi sinar $\mathrm{X}$ katalis $\mathrm{ZnO} / \mathrm{KA}$ dengan variasi $\mathrm{KA}$ $2 \%$, 5\%, dan $10 \%$ (\%wt) memperlihatkan pola yang senada, ternyata dengan adanya penambahan karbon aktif 2\%, 5\%, dan $10 \%$ tidak terlalu berpengaruh pada pola difraksi $\mathrm{ZnO}$, dan hanya sedikit merubah nilai intensitas dari masing-masing puncak yang ada. Pola difraksi sinar-X, juga dapat memberikan informasi mengenai ukuran kristal sampel. Dengan menggunakan persamaan Scherrer, didapatkan ukuran kristal dari $\mathrm{ZnO}, \mathrm{ZnO} / \mathrm{KA}$ dengan variasi $\mathrm{KA}$ $2 \%$, 5\%, dan $10 \%$ berturut-turut adalah 54,$481 ; 54,481 ; 54,482$; dan 54,482 nm. Jadi dapat disimpulkan bahwa penambahan karbon aktif, pada dasarnya tidak terlalu merubah ukuran kristal $\mathrm{ZnO}$

\section{Karaterisasi Dengan SEM}

Gambar 3.a merupakan hasil SEM ZnO dengan perbesaran 20000x, dapat diketahui dari gambar bahwa partikel-partikel $\mathrm{ZnO}$ menumpuk antar sesama partikelnya yang terlihat seperti gumpalan-gumpalan.

Untuk gambar 3.b merupakan hasil SEM dari karbon aktif, yang memperlihatkan bahwa karbon aktif berbentuk batangan dan memilki pori, pori ini yang nantinya akan membantu kerja katalitik dari ZnO. Gambar 3.c, d, dan e merupakan hasil SEM darikatalis $\mathrm{ZnO} / \mathrm{KA}$ dengan variasi KA $2 \%, 5 \%$, dan $10 \%$ (\%wt), dari hasil yang ada dapat dilihat bahwa dengan bertambahnya jumlah karbon aktif dalam $\mathrm{ZnO}$, partikel-partikel $\mathrm{ZnO}$ menempel dan menyebar ke permukaan karbon aktif. Karbon aktif menghalangi terjadinya penumpukan pada sesama partikel ZnO. Terhalangnya penumpukan partikel $\mathrm{ZnO}$ ini diasumsikan akan menyebabkan luas permukaan partikel $\mathrm{ZnO}$ semakin besar, yang nantinya akan meningkatkan aktifitas fotokatalitik $\mathrm{ZnO}$.

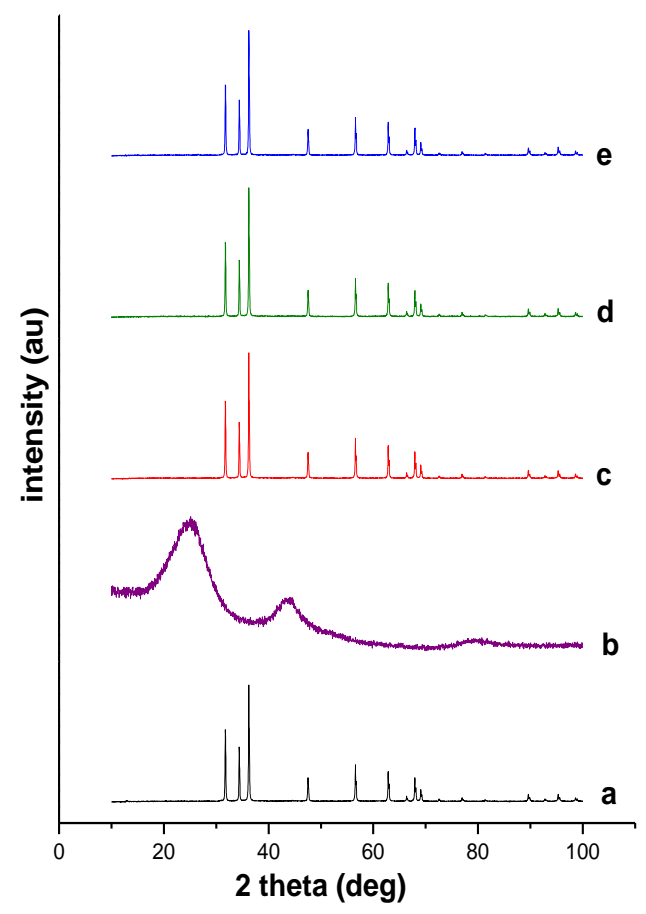

Gambar 2.Pola XRD dari a. $\mathrm{ZnO}$, b. Karbon Aktif, c. ZnO/KA 2\%, d. ZnO/KA 5\%, and e. $\mathrm{ZnO} / \mathrm{KA} 10 \%$.

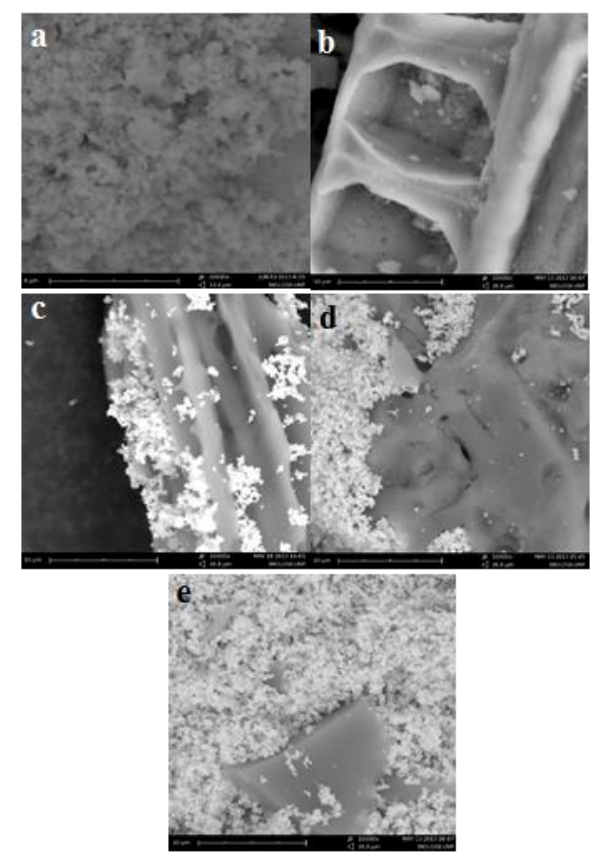

Gambar 3. Foto SEM dari a. ZnO 20000x, b. Karbon aktif, c. ZnO/KA 2\%, d. ZnO/KA $5 \%$, e. $\mathrm{ZnO} / \mathrm{KA} 10 \%$ 10000x. 
Uji Aktifitas Fotokatalitik Katalis ZnO, Karbon Aktif, dan Katalis $\mathrm{ZnO/KA}$

Uji aktifitas katalis $\mathrm{ZnO}$, karbon aktif, dan katalis $\mathrm{ZnO} / \mathrm{KA}$ dengan variasi $\mathrm{KA} 2 \%, 5 \%$, dan $10 \%$ (\%wt), dan tanpa katalis dilakukan pada degradasi larutan Rhodamin B 10 ppm serta penyinaran menggunakan lampu UV $(\lambda$ $=365 \mathrm{~nm}$ ) pada variasi lama penyinaran 1,2 , dan 3 jam. Hasil uji aktifitas fotokatalitik yang telah dilakukan, diperlihatkan pada diagram Gambar 4.

Berdasarkan Gambar 4, dari data hasil pengukuran menggunakan spektrofotometer UV-Vis pada panjang gelombang $551 \mathrm{~nm}$, untuk semua variabel $\mathrm{x}$ baik tanpa katalis, dengan katalis $\mathrm{ZnO}$, dan katalis komposit $\mathrm{ZnO} / \mathrm{KA}$ dengan berbagai variasi, yang memperlihatkan bahwa dengan semakin meningkatnya lama penyinaran maka persentase degradasi Rhodamin B semakin meningkat. Untuk tanpa katalis, peningkatan persen degradasi dikarenakan semakin lamanya waktu kontak antara larutan Rhodamin B dengan sinar UV.

Selanjutnya dengan penambahan katalis $\mathrm{ZnO}$, persen degradasi Rhodamin B meningkat dibandingkan dengan menggunakan penyinaran saja (tanpa katalis), hal ini dikarenakan telah adanya peranan $\mathrm{ZnO}$ sebagai fotokatalis yang aktif pada daerah sinar UV, sehingga akan menunjukkan kerja katalitiknya pada degradasi Rhodamin B.

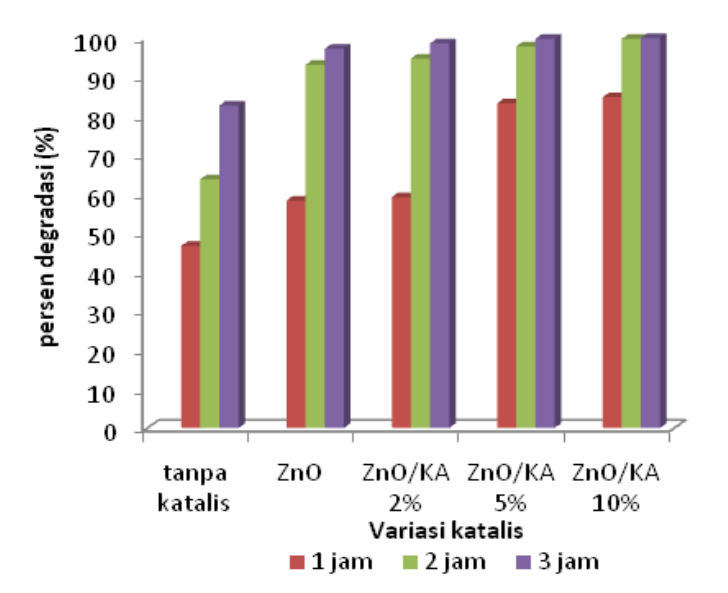

Gambar 4. Diagram persentase degradasi larutan Rhodamin B 10 ppm tanpa menggunakan katalis, katalis $\mathrm{ZnO}$, katalis $\mathrm{ZnO} / \mathrm{KA}$ dengan variasi $\mathrm{KA} 2 \%$; $5 \%$; dan $10 \%$.
Hal yang sama juga diperlihatkan pada penambahan komposit katalis $\mathrm{ZnO} / \mathrm{KA}$ dengan variasi KA 2\%, 5\%, dan 10\% (\%wt), yaitu persen degradasi Rhodamin B meningkat untuk setiap variasi lama penyinarannya. Semakin meningkatnya kadar karbon aktif maka kemampuan katalitik katalis $\mathrm{ZnO} / \mathrm{KA}$ dengan berbagai variasi juga meningkat, hal ini dikarenakan karbon aktif menghalangi terjadinya penggumpalan antar sesama partikel $\mathrm{ZnO}$ yang diasumsikan dapat memperbesar luas permukaan spesifik, sehingga akan meningkatkan aktifitas fotokatalitik $\mathrm{ZnO}$.

Pada penyinaran selama 3 jam, katalis $\mathrm{ZnO} / \mathrm{KA} 10 \%$ yang diujikan memberikan persen degradasi tertinggi yaitu $100 \%$. Ini menandakan bahwa larutan Rhodamin B 10 ppm telah terdegradasi sempurna, ditunjukkan pula dengan telah terjadinya perubahan warna yang awalnya merah muda pekat berubah menjadi bening. Ini membuktikan bahwa katalis $\mathrm{ZnO} / \mathrm{KA}$ dengan variasi KA $10 \%$ memberikan aktifitas paling baik dibandingkan katalis $\mathrm{ZnO}$, katalis $\mathrm{ZnO} / \mathrm{KA}$ dengan variasi $\mathrm{KA} 2 \%$; $5 \%$, dan tanpa katalis.Jadi dapat disimpulkan bahwa karbon aktif dapat meningkatkan peranan $\mathrm{ZnO}$ dalam mendegradasi senyawa Rhodamin B.

\section{KESIMPULAN}

Katalis $\mathrm{ZnO} /$ karbon aktif telah berhasil disintesis dengan metode solid state, dibuktikan dengan adanya data FTIR, XRD, dan SEM. Dari hasil FTIR, menunjukkan adanya serapan stretching $\mathrm{C}=\mathrm{C}$ yang diasumsikan berasal dari karbon aktif. Kemudian hasil XRD menunjukkan dengan adanya penambahan karbon aktif ternyata tidak terlalu merubah kristalinitas dan ukuran kristal dari ZnO. Hasil yang ditunjukkan oleh data SEM memperlihatkan bahwa dengan adanya karbon aktif dapat menghalangi terjadinya penumpukan antar sesama partikel $\mathrm{ZnO}$, dimana partikel $\mathrm{ZnO}$ menempel dan menyebar ke permukaan karbon aktif. Hasil uji aktifitas katalitik katalis $\mathrm{ZnO} / \mathrm{KA}$ dengan berbagai variasi, didapatkan semakin meningkatnya jumlah karbon aktif maka kemampuan katalitik $\mathrm{ZnO}$ juga meningkat, 
dapat disimpulkan bahwa karbon aktif membantu meningkatkan peranan $\mathrm{ZnO}$ dalam mendegradasi Rhodamin B.

\section{DAFTAR PUSTAKA}

1. Z. Han, L. Liao, Y. Wu, H. Pan, S. Shen, and J. Chen, Synthesis and Photocatalytic Application of Oriented Hierarchical $\quad \mathrm{ZnO} \quad$ Flower-rod Architectures, J. of Hazardous Materials, 100-106, (2010).

2. S.. Chakrabarti and B. K. Dutta, Photocatalytic degradation of model textile dyes in wastewater using $\mathrm{ZnO}$ as semiconductor catalyst, J. of Hazardous Materials, 269-278, (2004).

3. J. W. Andreasen, F. B. Rasmussen, S. Helveg, A. Molenbroek, K. Ståhl, M. M. Nielsend, and R. Feidenhans'la, Activation of a $\mathrm{Cu} / \mathrm{ZnO}$ catalyst for methanol synthesis, J. Appl. Cryst. 39, 209-221, (2006).

4. S. Lian, H. Huang, J. Zhang, Z. Kang, and Y. Liu, One-step Solvothermal Synthesis of ZnO-Carbon Composite Spheres Containing Different Ammounts of Carbon and Their Use as Visible Light Photocatalysts, J. Solid State Communication, 11, 003, (2012).

5. Amelia, Rizki., Pandapotan, Harlanto., dan Purwanto, Pembuatan dan Karakterisasi Katalis Karbon Aktif Tersulfonasi sebagai Katalis Ramah Lingkungan pada Proses Hidrolisis
Biomassa, J. Teknologi Kimia dan Industri, (2013).

6. E. Vourdrias, K. Fytianos, dan E. Bozani, Sorption-Desorption Isoterm of Dyes from Aqueous Solution and Waste Water with Different Sorbent Materials, J. Global Nest, 4, 1, (2002)

7. C. Jing, W. Xinlan, S. Xiaobao, and P. Rongkan, Synthesis of Zinc Oxide/ Activated Carbon Nano-Composites and Photodegradation of Rhodamine B, $J$. Environtmental Engineering Sci., 29, 6, 393-399, (2012).

8. S. Lian, H. Huang, J. Zhang, Z. Kang, and Y. Liu, One-step Solvothermal Synthesis of ZnO-Carbon Composite Spheres Containing Different Ammounts of Carbon and Their Use as Visible Light Photocatalysts, J. Solid State Communication, 11, 003, (2012).

9. W. Trisunaryanti, Handirofa, Triyono, dan S. Purwono, Preparasi, Karakterisasi dan Uji Aktifitas Katalis $\mathrm{CoMo} / \mathrm{ZnO}$ pada Konversi Etanol Menggunakan Metode Steam Reforming, J. Indo Chem, 9, 2, 195-200, (2009).

10. S. Darajat, H. Aziz, A. Alif, Seng Oksida $(\mathrm{ZnO})$ sebagai Fotokatalis pada Proses Degradasi Senyawa Biru Metilen, Jurnal Riset Kimia, 1, 2, hal. 179-186, (2008).

11. Stuart and Barbara., Infrared Spectroscopy Fundamental, Jhon Willey \& Sons Ltd, ISBNs: 0-470-85427-8 (HB); 0-470-85428-6 (PB), (2004). 